\title{
Recombination luminescence in $\mathrm{Li}_{2} \mathrm{~B}_{4} \mathrm{O}_{7}$ doped with manganese and copper
}

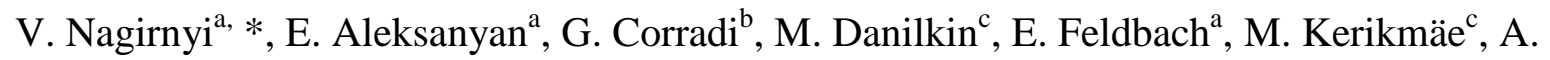

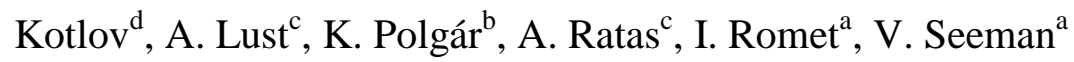 \\ ${ }^{a}$ Institute of Physics, University of Tartu, 142 Riia Str., 51014 Tartu, Estonia \\ ${ }^{b}$ Institute for Solid State Physics and Optics, Wigner Research Centre for Physics, Hungarian \\ Academy of Sciences, Budapest, P.O.B. 49, H-1525, Hungary \\ ${ }^{c}$ Institute of Chemistry, University of Tartu, Ravila 14a, 50411 Tartu, Estonia \\ ${ }^{d}$ DESY, Notkestrasse 85, 22607, Hamburg, Germany
}

\section{HIGHLIGHTS}

Doped $\mathrm{Li}_{2} \mathrm{~B}_{4} \mathrm{O}_{7}$ ceramics were studied by EPR and optical spectroscopy.

In $\mathrm{Li}_{2} \mathrm{~B}_{4} \mathrm{O}_{7}: \mathrm{Mn}$ ceramics $\mathrm{Mn}^{2+}$ emission is observed for the TSL peaks at 90 and $490 \mathrm{~K}$.

We propose the release of holes to be responsible for the dosimetric peak at $490 \mathrm{~K}$.

\begin{abstract}
Non-irradiated and irradiated ceramics of $\mathrm{Li}_{2} \mathrm{~B}_{4} \mathrm{O}_{7}: \mathrm{Mn}, \mathrm{Li}_{2} \mathrm{~B}_{4} \mathrm{O}_{7}: \mathrm{Mn}, \mathrm{Be}$, and $\mathrm{Li}_{2} \mathrm{~B}_{4} \mathrm{O}_{7}: \mathrm{Mn}, \mathrm{Cu}$ were studied using electron paramagnetic resonance and luminescence spectroscopy. The emission of $\mathrm{Mn}^{2+}$ centres is observed in the thermoluminescence spectra of the lowtemperature and dosimetric high-temperature glow peaks in irradiated samples. Arguments are given in favour of hole mobility being responsible for the dosimetric thermoluminescence peak at $490 \mathrm{~K}$ in $\mathrm{Li}_{2} \mathrm{~B}_{4} \mathrm{O}_{7}: \mathrm{Mn}$. The co-doping of $\mathrm{Li}_{2} \mathrm{~B}_{4} \mathrm{O}_{7}: \mathrm{Mn}$ with $\mathrm{Cu}^{+}$is shown to increase the sensitivity of the material to ionizing radiation.
\end{abstract}

Keywords: lithium tetraborate; electron paramagnetic resonance; thermoluminescence; manganese; hole trapping

* Corresponding author. Tel.: +372-7374769; fax: +372-7383033.

E-mail address: vitali.nagirnoi@ut.ee (V. Nagirnyi). 


\section{Introduction}

Lithium tetraborate $\left(\mathrm{Li}_{2} \mathrm{~B}_{4} \mathrm{O}_{7}\right.$ or $\left.\mathrm{LTB}\right)$ has been recognized as a promising tissueequivalent material for thermoluminescent dosimetry suitable in particular for neutron detection. Doped with multiple impurities $\mathrm{Cu}, \mathrm{Ag}, \mathrm{P}$ it demonstrates an outstanding sensitivity exceeding that of the well-known LiF:Mg,Ti (Prokic, 2002). Inspired by this research, a number of papers dealt with photo- and recombination luminescence of lithium tetraborate doped with single cationic impurities such as $\mathrm{Cu}, \mathrm{Ag}, \mathrm{Mn}, \mathrm{Eu}$ in order to clarify the role of particular impurities in recombination luminescence relevant for dosimetry (Ignatovich et al., 2004, 2007; Holovey et al., 2007; Corradi et al., 2008). It has been shown that $\mathrm{Cu}^{+}$or $\mathrm{Ag}^{+}$ ions play the role of efficient luminescence centres in $\mathrm{LTB} . \mathrm{Ag}^{+}$ions co-doped in $\mathrm{Li}_{2} \mathrm{~B}_{4} \mathrm{O}_{7}: \mathrm{Cu}$ were also shown to be efficient sensitizers for the $\mathrm{Cu}^{+}$emission (Patra et al., 2012). Recently $\mathrm{Li}_{2} \mathrm{~B}_{4} \mathrm{O}_{7}: \mathrm{Mn}$ was demonstrated to be an efficient dosimetric material with excellent $\gamma$ dose linearity and negligible fading upon storage (Annalakshmi et al., 2011). The red-orange emission of this system is ascribed to the $\mathrm{Mn}^{2+}$ ion (Ignatovich et al., 2007; Annalakshmi et al., 2011). However, the data on possible mechanisms of its appearance in recombination luminescence are controversial. It was suggested that a $\mathrm{Mn}^{2+}$ ion can trap a hole upon irradiation turning it to $\mathrm{Mn}^{3+}$ and then recombine with a thermally released electron giving rise to the $\mathrm{Mn}^{2+}$ luminescence (Ignatovich et al., 2012). On the other hand, no recharging of $\mathrm{Mn}$ ions has been registered by the method of electron paramagnetic resonance (EPR) within the region of irradiation dose linearity, and hole trapping at a bridging oxygen adjacent to a $\mathrm{Mn}^{2+}$ at a tetrahedrally coordinated $\mathrm{B}^{3+}$ position has been suggested (Danilkin et al., 2010). The present paper is an attempt, based on spectroscopic and EPR studies of doped LTB ceramics, to find more arguments which could help in a direct or indirect way to clarify the processes responsible for the dosimetric peaks in Mn-doped lithium tetraborate.

\section{Experimental}

All measurements were done on sintered ceramics prepared at the Institute of Chemistry, University of Tartu according to the following procedure. Lithium tetraborate was obtained by the reaction:

$$
\mathrm{Li}_{2} \mathrm{CO}_{3}+4 \mathrm{H}_{3} \mathrm{BO}_{3}=\mathrm{Li}_{2} \mathrm{~B}_{4} \mathrm{O}_{7}+6 \mathrm{H}_{2} \mathrm{O}+\mathrm{CO}_{2}
$$

To produce $\mathrm{Li}_{2} \mathrm{~B}_{4} \mathrm{O}_{7}$ doped with $\mathrm{Cu}, \mathrm{Mn}$ or $\mathrm{Be}$, the powders of $\mathrm{CuSO}_{4}, \mathrm{MnCO}_{3}$ or $\mathrm{BeO}$, respectively, were added to $\mathrm{Li}_{2} \mathrm{~B}_{4} \mathrm{O}_{7}$ typically in amounts of $0.13-0.26 \mathrm{~mol} \%$ at the stage 
of initial synthesis in water suspension under continuous stirring and heating of the mixture. The corresponding amounts stand further for impurity concentrations in the samples. The residual water and $\mathrm{CO}_{2}$ were removed by annealing the mixture at $823 \mathrm{~K}$ for 120 min under constant nitrogen flow. The resulting material was ground in a mortar, and tablets were pressed. The ceramic tablets were sintered at various temperatures below the melting point of lithium tetraborate at $1190 \mathrm{~K}$. The diameter of sintered tablets was $4.5 \mathrm{~mm}$.

Excitation and emission spectra of the samples excited by synchrotron radiation were measured at the SUPERLUMI station of HASYLAB at DESY, Germany (Zimmerer, 2007). The emission was analysed with a SpectraPro308i (Acton) spectrograph and a Hamamatsu photomultiplier (PMT) R6358P. The integral thermostimulated luminescence (TSL) curves of irradiated samples were recorded at a heating rate $0.4 \mathrm{~K} / \mathrm{s}$ with a H5783P PMT. TSL spectra were measured in each TSL peak with a SpectraPro2300i grating monochromator equipped with a Hamamatsu H6240-01 photon counting head using fast scanning within 20-30 s depending on spectral range, which, for the given heating rate, corresponded to a temperature interval of 10-15 K. The samples were irradiated by X-rays $(53 \mathrm{kV}, 15 \mathrm{~mA}$, dose rate $32 \mathrm{~Gy} / \mathrm{s} / \mathrm{cm}^{2}$ or $20 \mathrm{kV}, 0.4 \mathrm{~mA}$, dose rate $\left.0.01 \mathrm{~Gy} / \mathrm{s} / \mathrm{cm}^{2}\right)$, electrons $(5 \mathrm{kV}, 0.3 \mu \mathrm{A})$ or with a ${ }^{239} \mathrm{Pu}$ radiation source $\left(6.02 \times 10^{5}\right.$ particles per second, dose rate $\left.0.008 \mathrm{~Gy} / \mathrm{s} / \mathrm{cm}^{2}\right)$.

\section{Results and discussion}

The emission spectrum of a $\mathrm{Li}_{2} \mathrm{~B}_{4} \mathrm{O}_{7}: \mathrm{Mn}(0.13 \mathrm{~mol} \%)$ ceramic sample at $9 \mathrm{~K}$ reveals a strong, slightly asymmetric band peaked at $2.03 \mathrm{eV}$ (Fig. 1, curve 1). The spectrum is similar to that reported by Kelemen et al. (2007), but slightly differs from the photoluminescence spectrum reported by Annalakshmi et al. (2011). The excitation spectrum of the $2.03 \mathrm{eV}$ emission consists of two main bands at 7 and $7.54 \mathrm{eV}$ situated in the region adjacent to the fundamental absorption edge of the host (curve 2) and the bands at 3-4 eV (curve 2'), which are weaker by two orders of magnitude. The latter were measured with a laboratory setup (deuterium lamp DDS-400, double-quartz monochromator DMR-4) and normalized at $3.8 \mathrm{eV}$ to the spectra taken at the SUPERLUMI station. The excitation spectrum of the emission of self-trapped excitons (STEs) measured for the same sample is shown for comparison by curve 4. Its intensity follows the shape of the fundamental absorption edge in the region 7.6-8.3 eV and then sharply decreases near $10 \mathrm{eV}$ (see also Corradi et al., 2008). Excitation within the described region produces a broad emission band with maximum at $3.65 \mathrm{eV}$ (inset, curve 3). 
Following the previous works (Kelemen et al., 2007; Ignatovich et al., 2012) the emission at $2.03 \mathrm{eV}$ is ascribed to the transitions in $\mathrm{Mn}^{2+}$ ions. The 2.03-eV emission and its excitation spectrum are well-resolved, which is an indirect argument in favour of the suggestion that the $\mathrm{Mn}^{2+}$ centre responsible for this emission occupies a well-defined position in the lattice. No other strong emission, which could be ascribed to $\mathrm{Mn}^{2+}$ in a different position was detected. The asymmetry of the $2.03-\mathrm{eV}$ emission on the long-wavelength side is caused by the admixture of a weak red emission with maximum near $1.92 \mathrm{eV}$ (curve 5), whose excitation spectrum is much less featured (curve 6). The latter is represented by a broad structureless band covering the region between 5 and $8 \mathrm{eV}$. The $1.92-\mathrm{eV}$ emission is present in all LTB:Mn and LTB:Mn,Be ceramics, however, its relative intensity increases with Mn concentration and is especially high in heavily double-doped samples with the Mn and Be concentrations reaching $0.26 \mathrm{~mol} \%$. In such samples the emission at $1.92 \mathrm{eV}$ dominates the 2.03-eV emission. For better visibility the emission and excitation spectra of the $1.92-\mathrm{eV}$ band are shown in Fig. 1 for the LTB:Be( $0.13 \mathrm{~mol} \%), \mathrm{Mn}(0.13 \mathrm{~mol} \%)$ ceramics. One can suggest that this emission originates from a family of complex $\mathrm{Mn}^{2+}$ centres with various structures possibly situated at irregular sites or grain boundaries.

To identify the centres responsible for the recombination luminescence observed upon heating the sample irradiated either at low or room temperature (RT), we compared the TSL spectra of irradiated samples with the emission spectra of the same samples previously measured under photoexcitation.

The TSL curve of a LTB:Mn( $0.13 \mathrm{~mol} \%)$ ceramics irradiated by $5-\mathrm{keV}$ electrons at 5 $\mathrm{K}$ is shown in Fig. 2. In this curve, the peak at $200 \mathrm{~K}$ depends strongly on sample preparation conditions and is related to some unidentified defects. Two peaks above $300 \mathrm{~K}$ are related to the manganese impurity and will be discussed later on. Here we shall focus on the TSL peak near $90 \mathrm{~K}$. Our recent studies have shown that it is observed in all lithium tetraborate samples either doped or not, and for that reason one can conclude that at least one recombination partner responsible for the TSL at this temperature is of intrinsic nature. According to Swinney et al. (2010) a hole is either self-trapped or stabilized by $\mathrm{Li}^{+}$vacancy, while an electron is trapped at an oxygen vacancy in undoped crystals. The hole centre disappears completely at temperatures above $90 \mathrm{~K}$. This might be considered as an indication for the hole becoming mobile first at this temperature. Important information on the nature of the electron trap in doped crystals can be obtained from the study of the TSL spectra measured in the region of the $90 \mathrm{~K}$ peak. It is clearly seen from the inset in Fig. 2 that the emission of $\mathrm{Mn}^{2+}$ ions is dominant in the TSL spectrum of the $90 \mathrm{~K}$ TSL peak in LTB:Mn ceramics. This means 
that either the recombination takes place at manganese or the excitation is transferred to a neighbouring $\mathrm{Mn}^{2+}$ ion upon recombination. The situation is similar to the one observed in silver or copper doped ceramics and crystals, where both the dopant emission and the emission of perturbed self-trapped excitons are observed in the TSL spectra at $90 \mathrm{~K}$ (Corradi, in press).

The analysis of the shape of the TSL peak at $90 \mathrm{~K}$ in LTB:Mn demonstrates the first order kinetics and gives the activation energy of the recombination process as $E_{\mathrm{a}}=44 \mathrm{meV}$ and an extremely low frequency factor of a value $p=2.8$. Such a small value can be indicative of recombination between trapped charge carriers in close pairs, when none of the carriers becomes really mobile (the case of so-called centre-to-centre recombination) (see, e.g., Meijerink, Blasse, 1991). The possibility of the charge carrier recombination energy transfer to the $\mathrm{Mn}^{2+}$ ion is a most important result necessary for the understanding of the processes responsible for the high-temperature dosimetric peaks of Mn doped lithium tetraborate.

The glow curve of LTB:Mn(0.13 mol\%) irradiated during $100 \mathrm{~s}$ at RT with a ${ }^{239} \mathrm{Pu}$ radiation source is shown in Fig. 3, curve 1. It contains two main TSL peaks in the regions of $335-345 \mathrm{~K}$ and $470-510 \mathrm{~K}$. The former is subject to fast fading at RT and has no practical importance. The high-temperature peak is very stable and for that reason is perspective from the viewpoint of thermal readout of the stored radiation dose. The processes responsible for the recombination luminescence in this peak are not clarified. The emission spectrum of the TSL measured in the maximum of the peak is close to the photoluminescence spectrum measured at RT (inset in Fig. 3). Correspondingly, like in the case of the $90 \mathrm{~K}$ TSL the recombination takes place at the $\mathrm{Mn}^{2+}$ ion or near to it.

By analysing the EPR signal in non-irradiated LTB:Mn exhibiting partly resolved hyperfine splittings of the order of several mT (Danilkin et al., 2010) it has been shown that $\mathrm{Mn}^{2+}$ can occupy two different sites, substituting for a $\mathrm{Li}^{+}$ion or breaking the boron-oxide network and substituting for $\mathrm{a}^{3+}$ in a fourfold-coordinated site. No decrease of this EPR signal was observed under X-irradiation ( $53 \mathrm{kV}, 15 \mathrm{~mA}$ ) of LTB:Mn ceramics up to the dose of $1 \mathrm{kGy}$. Considering that such a dose corresponds to the upper dose linearity limit of the material for $\gamma$-irradiation (Annalakshmi et al., 2011), one can conclude that $\mathrm{Mn}^{2+}$ recharging plays no remarkable role in the energy storage process. We did observe the decrease of the $\mathrm{Mn}^{2+} \mathrm{EPR}$ signal for doses exceeding $2 \mathrm{kGy}$, however, in this case an irreversible degradation of the material takes place. It is worth mentioning that the irradiation dose $12 \mathrm{kGy}$ used by Kelemen at al. (2007), who reported on $\mathrm{Mn}^{2+}$ recharging under powerful electron pulses, also exceeded the dose linearity limit. 
If the $\mathrm{Mn}^{2+}$ concentration in either site does not change under irradiation of the

sample, while the dosimetric response is linear within six orders of magnitude, one can assume that charge carriers are trapped near the $\mathrm{Mn}^{2+}$ ions. Indeed, the $\mathrm{Mn}^{2+}$ ion with extra positive charge either compensated by a neighbouring $\mathrm{Li}^{+}$vacancy or not should be capable of electron trapping. The $\mathrm{Mn}^{2+}$ ion replacing trivalent boron and causing a broken oxygen bond in this site should form an efficient hole trapping centre.

The EPR spectrum recorded at RT after X-irradiation of $\mathrm{Li}_{2} \mathrm{~B}_{4} \mathrm{O}_{7}: \mathrm{Mn}$ is shown in Fig. 4 (for demonstration purposes a high dose of about $11 \mathrm{kGy}$ was used). In addition to the $\mathrm{Mn}^{2+}$ lines seen in non-irradiated samples (Danilkin et al., 2010) a new sextet structure with a splitting of the order of $1 \mathrm{mT}$ can be discerned in the region 325-330 $\mathrm{mT}$. This may correspond to a radiation centre with the unpaired spin having super-hyperfine interaction with a neighbouring Mn nucleus.

The recorded spectrum only corresponds to one of the principal values of the g-tensor $(\mathrm{g}=1.997 \pm 0.001)$. Despite the negative shift of this component, the similarity of the splitting constant to that of a hole centre localized near a $\mathrm{Be}^{2+}$ ion in a $\mathrm{B}^{3+}$ position (Kerikmäe, in press) allows one to suggest a hole nature also for the centre in $\mathrm{Li}_{2} \mathrm{~B}_{4} \mathrm{O}_{7}: \mathrm{Mn}$. This might be correct if the components with positive shifts could not be observed in ceramics (experiments in single crystal are needed).

Whatever the nature of the centre under discussion, its EPR signal completely disappears exactly in the temperature region of the dosimetric peak at $490 \mathrm{~K}$ (Fig. 5, curve2). Consequently, this centre is one of the partners in the recombination luminescence process responsible for the dosimetric peak. To reveal the sign of the observed process, $\mathrm{Li}_{2} \mathrm{~B}_{4} \mathrm{O}_{7}: \mathrm{Mn}, \mathrm{Be}$ samples with mixed doping were studied by the EPR method. It has been shown by Kerikmäe et. al. (in press) that the hole localized near a $\mathrm{Be}^{2+}$ ion in a $\mathrm{B}^{3+}$ site in $\mathrm{Li}_{2} \mathrm{~B}_{4} \mathrm{O}_{7}: \mathrm{Be}$ is thermally released at $550 \mathrm{~K}$. We found that in $\mathrm{Li}_{2} \mathrm{~B}_{4} \mathrm{O}_{7}: \mathrm{Mn}, \mathrm{Be}$ samples, the decrease of the EPR signal of Mn-related radiation-induced centre at $490 \mathrm{~K}$ is accompanied by the increase of the EPR signal of the Be-related hole centre. As expected, the effect strongly depends on the relative concentration of $\mathrm{Mn}^{2+}$ and $\mathrm{Be}^{2+}$, whereas the increase reaches $15 \%$ in $\mathrm{Li}_{2} \mathrm{~B}_{4} \mathrm{O}_{7}: \mathrm{Mn}(0.13 \mathrm{~mol} \%), \mathrm{Be}(0.13 \mathrm{~mol} \%)$. This confirms the hole nature of the recombination luminescence observed in the dosimetric peak at $490 \mathrm{~K}$ in $\mathrm{Li}_{2} \mathrm{~B}_{4} \mathrm{O}_{7}: \mathrm{Mn}$. As $\mathrm{Mn}^{2+}$ luminescence is observed in this process, one can suppose the release of a hole localized near $\mathrm{Mn}^{2+}$ at a $\mathrm{B}^{3+}$ site and its recombination with an electron trapped near another $\mathrm{Mn}^{2+}$ localized at a $\mathrm{Li}^{+}$site. A detailed model still needs clarification. Finally, we found that the dosimetric peak is observed practically at the same temperatures in $\mathrm{Li}_{2} \mathrm{~B}_{4} \mathrm{O}_{7}$ :Mn ceramics co- 
doped with $\mathrm{Cu}^{+}$(Fig. 3, curve 2), which has been shown to substitute exclusively for $\mathrm{Li}^{+}$ions (see Corradi et al., 2008). In this case the $\mathrm{Cu}^{+}$emission peaked at $3.35 \mathrm{eV}$ is observed in TSL spectra, which is an indirect confirmation that the hole is released from another, manganeserelated centre. We found that under the same irradiation conditions the integral intensity in $\mathrm{Li}_{2} \mathrm{~B}_{4} \mathrm{O}_{7}: \mathrm{Mn}, \mathrm{Cu}$, even with non-optimized impurity concentrations, is higher than that in $\mathrm{Li}_{2} \mathrm{~B}_{4} \mathrm{O}_{7}: \mathrm{Mn}$.

Several questions have to be answered in the course of further studies. It is not clear why only one type of $\mathrm{Mn}^{2+}$ ions reveals itself in photoluminescence. The counterpart of the radiation-induced centre has yet to be found possibly by the EPR method. In order to obtain more detailed information on impurity and radiation-induced centres, after optimization of the methods for the introduction of $\mathrm{Mn}^{2+}$ into various sites, more $\mathrm{Li}_{2} \mathrm{~B}_{4} \mathrm{O}_{7}: \mathrm{Mn}$ samples including single crystals have to be grown and investigated.

\section{Conclusions}

It was shown by electron paramagnetic resonance and luminescence spectroscopy that $\mathrm{Mn}^{2+}$ ions play an essential role in the recombination luminescence of irradiated sintered ceramics of $\mathrm{Li}_{2} \mathrm{~B}_{4} \mathrm{O}_{7}: \mathrm{Mn}, \mathrm{Li}_{2} \mathrm{~B}_{4} \mathrm{O}_{7}: \mathrm{Mn}, \mathrm{Cu}$, and $\mathrm{Li}_{2} \mathrm{~B}_{4} \mathrm{O}_{7}: \mathrm{Mn}, \mathrm{Be}$ in the whole temperature range studied. Recharging of manganese ions is not an efficient process under moderate irradiation doses. We assume, however, that electrons and holes are trapped near $\mathrm{Mn}^{2+}$ ions occupying different sites in the lattice. Based on indirect arguments it is possible to suggest that for $\mathrm{Li}_{2} \mathrm{~B}_{4} \mathrm{O}_{7}: \mathrm{Mn}$ the dosimetric peak at $490 \mathrm{~K}$ originates from the thermal release of a hole localized near $\mathrm{Mn}^{2+}$ at $\mathrm{a} \mathrm{B}^{3+}$ site followed by its recombination with an electron trapped near $\mathrm{Mn}^{2+}$ localized at a $\mathrm{Li}^{+}$site. The co-doping of $\mathrm{Li}_{2} \mathrm{~B}_{4} \mathrm{O}_{7}: \mathrm{Mn}$ with $\mathrm{Cu}^{+}$introduces new trapping and recombination sites, which increases the sensitivity of the material to ionizing radiation.

\section{Acknowledgements}

This work was supported by the European Community's Seventh Framework Programme (FP7/2007-2013) under grant $\mathrm{n}^{\circ}$ 226716, a Cooperation Project of the Estonian and Hungarian Academies of Sciences, and the Estonian Science Foundation (Grants 8893 and 9222). 


\section{References}

Annalakshmi, O., Jose, M.T., Amarendra, G., 2011. Dosimetric characteristics of manganese doped lithium tetraborate - An improved TL phosphor. Radiat. Meas. 46, 669-675.

Corradi, G., Nagirnyi, V., Kotlov, A., Watterich, A., Kirm, M., Polgár, K., Hofstaetter, A., Meyer, M., 2008. Investigation of $\mathrm{Cu}$-doped $\mathrm{Li}_{2} \mathrm{~B}_{4} \mathrm{O}_{7}$ single crystals by electron paramagnetic resonance and time-resolved optical spectroscopy. J. Phys.: Condens. Matter 20, 025216 (9pp).

Danilkin, M., Jaek, I., Kerikmäe, M., Lust, A., Mändar, H., Pung, L., Ratas, A., Seeman, V., Klimonsky, S., Kuznetsov, V., 2010. Storage mechanism and OSL-readout possibility of $\mathrm{Li}_{2} \mathrm{~B}_{4} \mathrm{O}_{7}: \mathrm{Mn}$ (TLD-800). Radiat. Meas. 45, 562-565.

Holovey, V.M., Sidey, V.I., Lyamayev, V.I., Puga, P.P., 2007. Influence of reducing annealing on the luminescent properties of $\mathrm{Li}_{2} \mathrm{~B}_{4} \mathrm{O}_{7}: \mathrm{Cu}$ single crystals. J. Lumin. 126, 408412.

Ignatovych, M., Holovey, V., Watterich, A., Vidóczy,T., Baranyai, P., Kelemen, A., Chuiko, O., 2004. Luminescence characteristics of $\mathrm{Cu}$ - and Eu-doped $\mathrm{Li}_{2} \mathrm{~B}_{4} \mathrm{O}_{7}$. Radiat. Meas. 38, 567570 .

Ignatovych, M., Holovey, V., Vidóczy, T., Baranyai, P., Kelemen, A., 2007. Spectral study on manganese- and silver-doped lithium tetraborate phosphors. Radiat. Phys. Chem. 76, 15271530.

Ignatovych, M., Fasoli, M., Kelemen, A., 2012. Thermoluminescence study of Cu, Ag and Mn doped lithium tetraborate single crystals and glasses. Radiat. Phys. Chem. 81, 1528-1532. Kelemen, A., Ignatovych, M., Holovey, V., Vidóczy, T., Baranyai, P., 2007. Effect of irradiation on photoluminescence and optical absorption spectra of $\mathrm{Li}_{2} \mathrm{~B}_{4} \mathrm{O}_{7}: \mathrm{Mn}$ and $\mathrm{Li}_{2} \mathrm{~B}_{4} \mathrm{O}_{7}$ :Ag single crystals. Radiat. Phys. Chem. 76, 1531-1534.

Kerikmäe,M.,Danilkin, M., Lusta, A., Nagirnyi, V., Pung, L., Ratas, A., Romet, I., Seeman, V., Hole traps and thermoluminescence in $\mathrm{Li}_{2} \mathrm{~B}_{4} \mathrm{O}_{7}$ :Be. Radiat. Meas. (P-Tue-67).

Meijerink, A., Blasse, G., 1991. Photostimulated luminescence and thermally stimulated luminescence of some new X-ray storage phosphors. J. Phys. D: Appl. Phys. 24, 626-632. Patra, G.D., Tyagi, M., Desai, D.G., Tiwari, B., Sen, S., Gadkari, S.C., 2012. Photoluminescence properties of $\mathrm{Cu}$ and $\mathrm{Ag}$ doped $\mathrm{Li}_{2} \mathrm{~B}_{4} \mathrm{O}_{7}$ single crystals at low temperatures. $\mathrm{J}$. Lumin. 132, 1101-1105. 
Prokic, M., 2002. Dosimetric characteristics of $\mathrm{Li}_{2} \mathrm{~B}_{4} \mathrm{O}_{7}: \mathrm{Cu}, \mathrm{Ag}, \mathrm{P}$ solid TL detectors. Radiat. Prot. Dosim. 100, 265-268.

Swinney, M.W., McClory, J.W., Petrosky, J.C., Yang, Shan, Brant, A.T., Adamiv, V.T., Burak, Ya.V., Dowben, P.A., Halliburton, L.E., 2010. Identification of electron and hole traps in lithium tetraborate $\mathrm{Li}_{2} \mathrm{~B}_{4} \mathrm{O}_{7}$ crystals: Oxygen vacancies and lithium vacancies. J. Appl. Phys. 107, 113715 (9 pp.).

Zimmerer, G., 2007. SUPERLUMI: A unique setup for luminescence spectroscopy with synchrotron radiation. Radiat. Meas. 42, $859-864$. 


\section{Figure captions}

Fig. 1. Emission spectrum at the excitation energy $E_{\mathrm{exc}}=7 \mathrm{eV}(1)$, the excitation spectrum of the $2.03 \mathrm{eV}$ emission (2,2'), emission (3) and excitation (4) spectra measured for the STE emission of a LTB:Mn(0.13 mol\%) sample. Emission spectrum at $\mathrm{E}_{\mathrm{exc}}=6.4 \mathrm{eV}(5)$ and excitation spectrum of the $1.92 \mathrm{eV}$ emission (6) of a LTB:Be(0.13 mol\%), $\mathrm{Mn}(0.13 \mathrm{~mol} \%)$ sample. $\mathrm{T}=9 \mathrm{~K}$.

Fig. 2. Glow curve of a LTB:Mn( $0.13 \mathrm{~mol} \%)$ ceramics irradiated by an electron beam ( $5 \mathrm{keV}$, $0.3 \mu \mathrm{A}$ ) for $10 \mathrm{~min}$ at $5 \mathrm{~K}(1)$. Inset: a TSL spectrum measured in the interval $87-98 \mathrm{~K}$ (line with dots) compared to the PL spectrum of $\mathrm{Mn}^{2+}$ centres (solid line).

Fig. 3. Glow curves of the LTB:Mn $(0.13 \mathrm{~mol} \%)$ ceramics irradiated with a ${ }^{239} \mathrm{Pu}$ radiation source for $100 \mathrm{~s}(1)$ and LTB: $\mathrm{Mn}(0.13 \mathrm{~mol} \%), \mathrm{Cu}(0.13 \mathrm{~mol} \%)$ ceramics X-irradiated $(20 \mathrm{kV}$, $0.4 \mathrm{~mA}$ ) $20 \mathrm{~min}(2)$ at $295 \mathrm{~K}$. Inset: a TSL spectrum measured in the interval 498-515 K (line with dots) compared to the PL spectrum of $\mathrm{Mn}^{2+}$ centres (solid line) measured at $300 \mathrm{~K}$ for the LTB:Mn(0.13 mol\%) ceramics.

Fig. 4. EPR spectrum (X-band, $975 \mathrm{kHz}$ modulation) of a radiation-induced centre in $\mathrm{Li}_{2} \mathrm{~B}_{4} \mathrm{O}_{7}: \mathrm{Mn}$ recorded at room temperature after X-irradiation.

Fig. 5. Glow curves of the LTB: $\mathrm{Mn}(0.13 \mathrm{~mol} \%)$ ceramics irradiated with a ${ }^{239} \mathrm{Pu}$ radiation source for $100 \mathrm{~s}(1)$ and the annealing of EPR signal of the radiation-induced centre (2) (see text for details). The linear heating rate was $0.15 \mathrm{~K} / \mathrm{s}$. The EPR signal was measured at room temperature. 
Figure 1

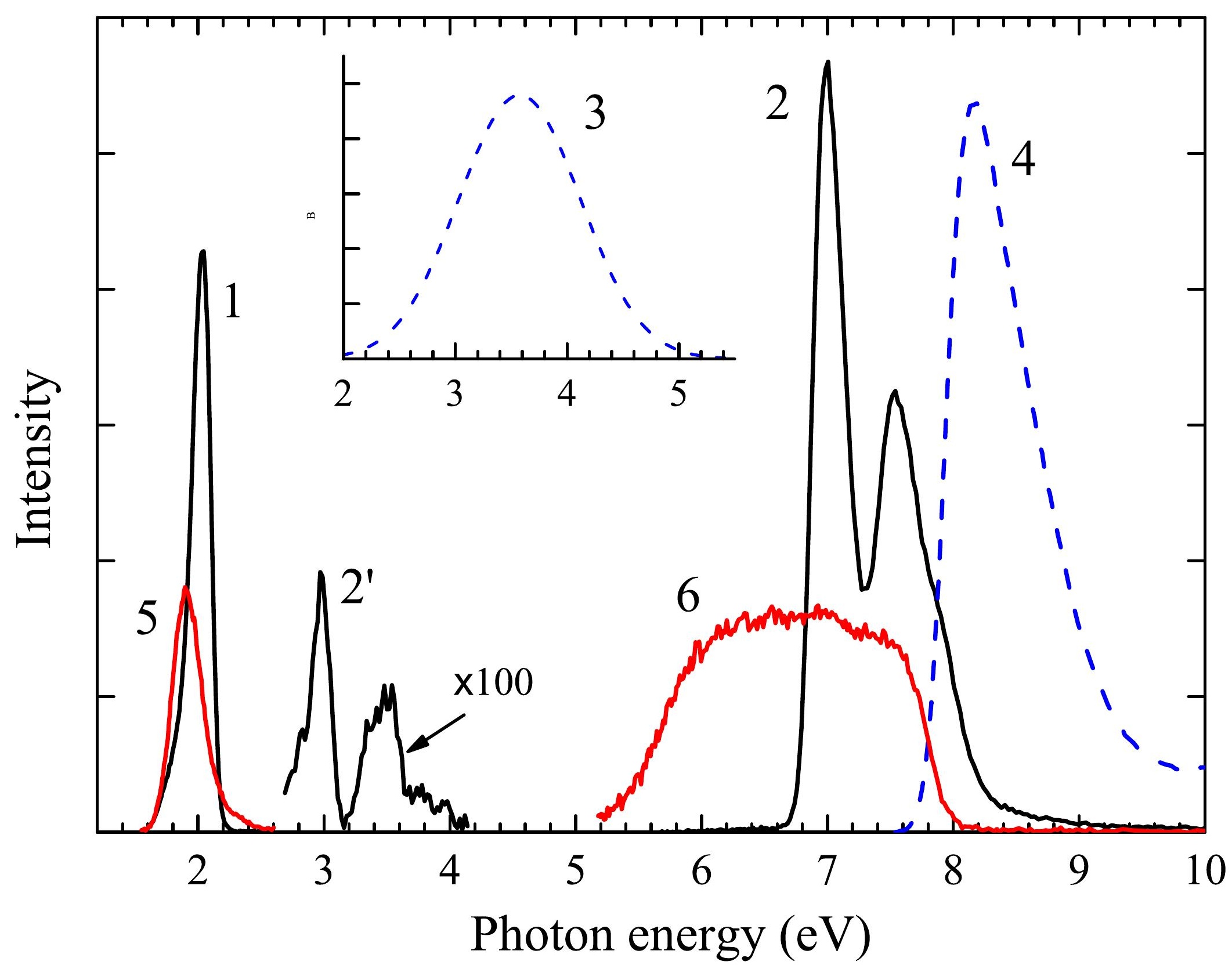




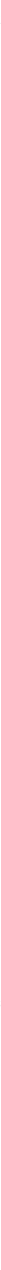




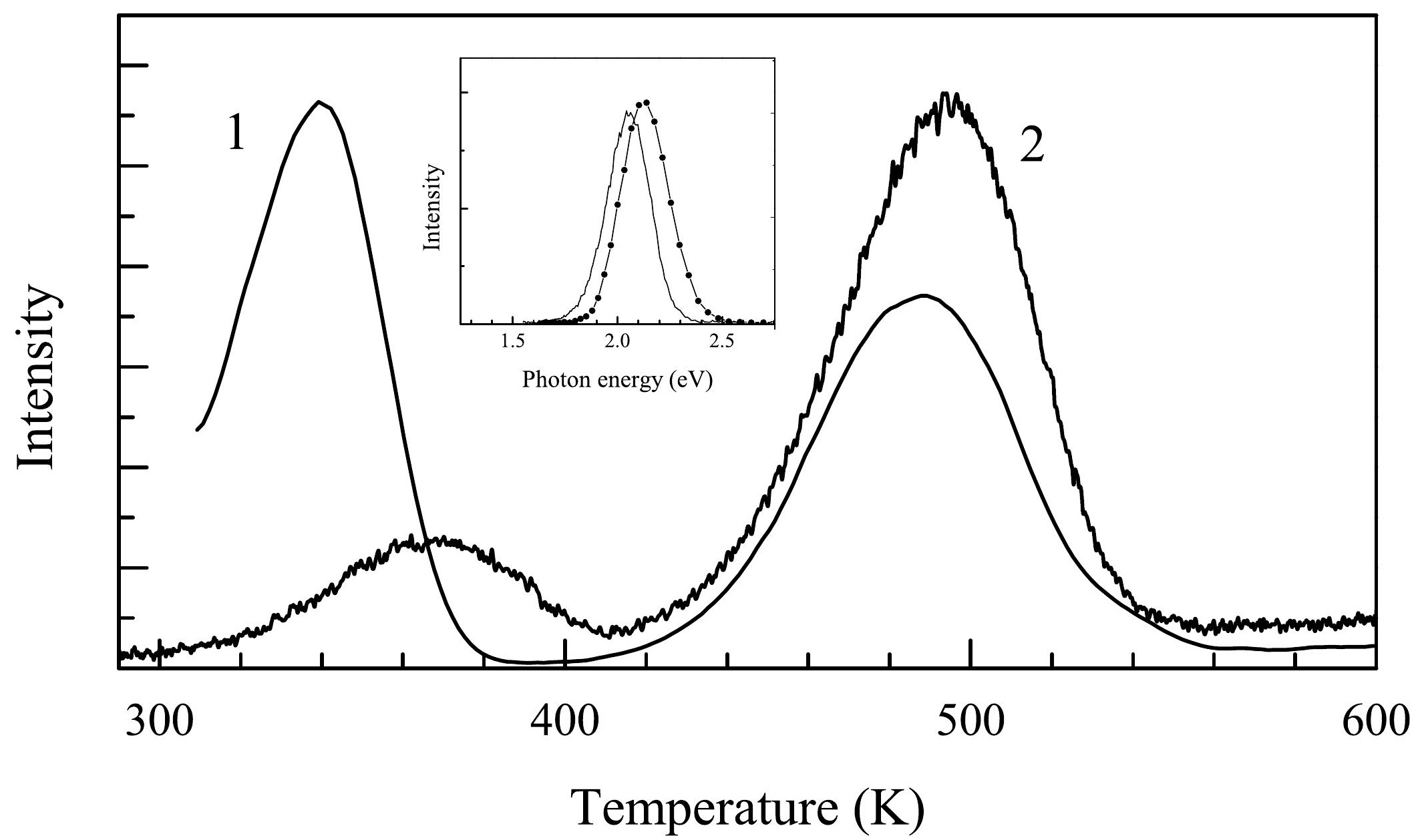


Figure 4

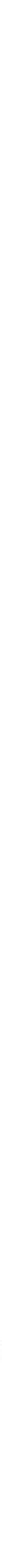

\section{Figure 4}

. 


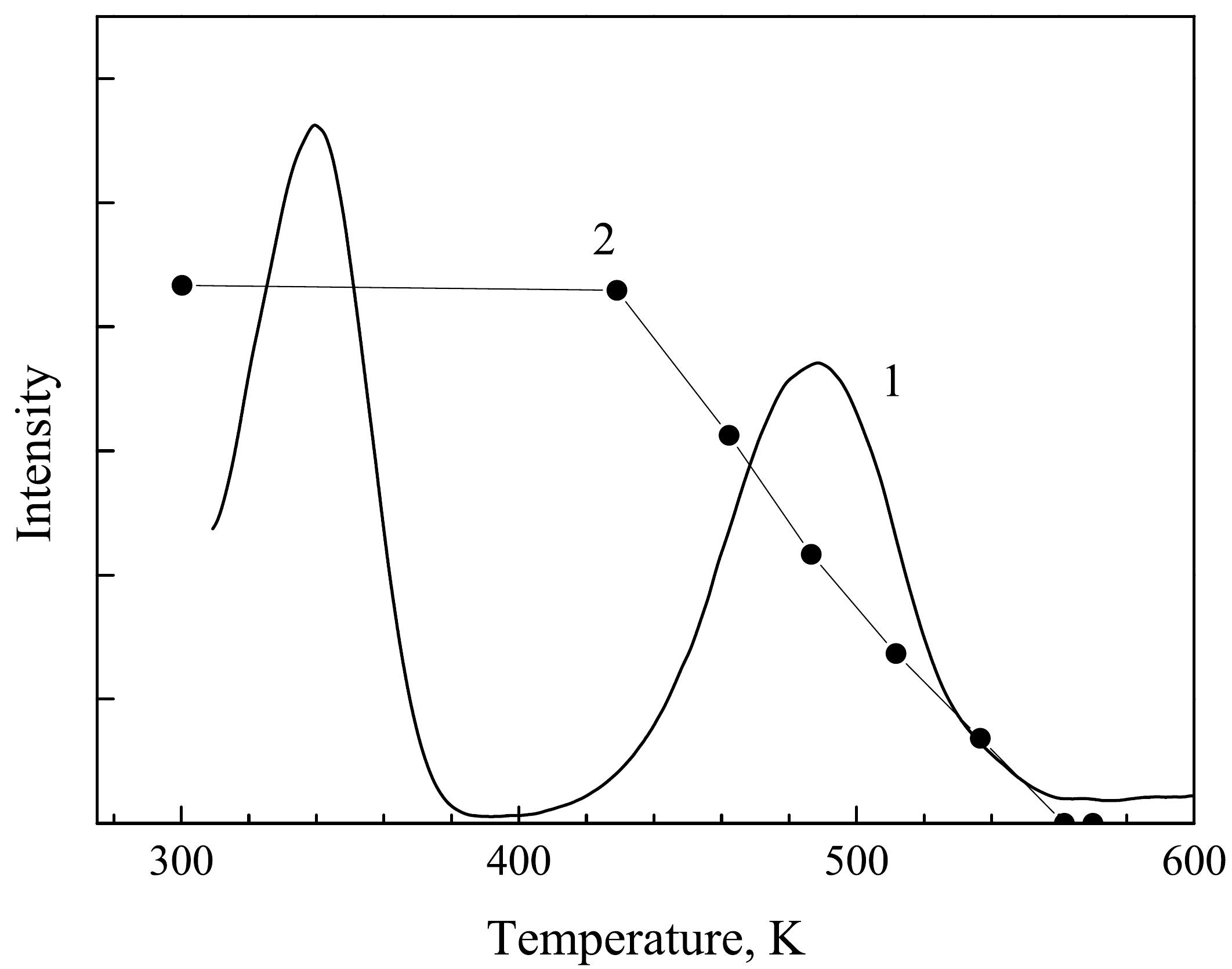

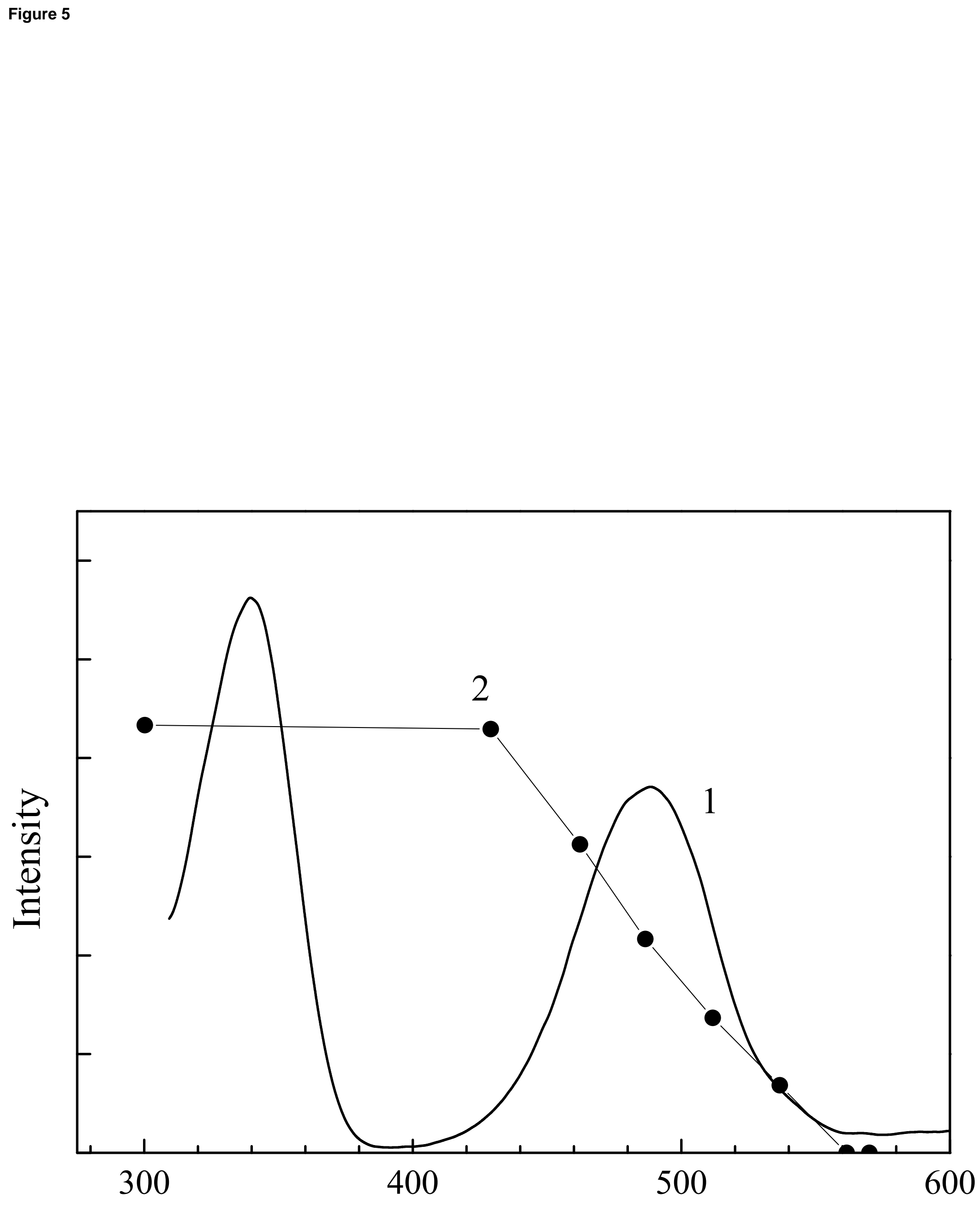

Temperature, $\mathrm{K}$ 